\title{
Erratum to: On the Influence of the Propagation Channel in the Performance of Energy-Efficient Geographic Routing Algorithms for Wireless Sensor Networks (WSN)
}

\author{
P. Padilla • J. Camacho - G. Maciá-Fernández • J. E. Díaz-Verdejo • \\ P. García-Teodoro • C. Gómez-Calero
}

Published online: 28 June 2012

C) Springer Science+Business Media, LLC. 2012

\section{Erratum to: Wireless Pers Commun DOI 10.1007/s11277-012-0676-5}

The Acknowledgments section in the original publication was incomplete. The text shown below is complete.

Acknowledgments This work has been supported by the Spanish Government (Comisión Interministerial de Ciencia y Tecnología) under the "SuMA" project (REF: TEC2011-22579), and the PYR-2012-11 CEI BioTIC GENIL project (PYR-2012-CEB09-0010/MICINN).

The online version of the original article can be found under doi:10.1007/s11277-012-0676-5.

P. Padilla $(\varangle)$ · J. Camacho · G. Maciá-Fernández · J. E. Díaz-Verdejo · P. García-Teodoro

Signal Theory, Telematics and Communications Department, CITIC, University of Granada, Granada,

Spain

e-mail: pablopadilla@ugr.es

C. Gómez-Calero

Radiation Group, Signal, Systems and Radiocommunications Department, Technical University of Madrid, Madrid, Spain 